\title{
UMA EDUCAÇÃO AMBIENTAL PARA ALÉM DA PANDEMIA: APRENDIZADOS DECOLONIAIS COM OUTRAS COMUNIDADES E COM OUTRAS PEDAGOGIAS
}

Fábio Pessoa Vieira ${ }^{1}$

Resumo: Para a compreensão de uma multiplicidade de espaços sustentáveis existentes no mundo, apresento uma Educação Ambiental que se alicerça em outras pedagogias presentes em comunidades tradicionais. Ao ter como suporte a noção de envolvimento ambiental e o Bem Viver, lanço mão da decolonialidade visando me atualizar perante a crise mundial de saúde, decorrente da pandemia da COVID-19, no que se refere à outras possibilidades de atuação como educador ambiental. Os resultados criam condições para os educadores ambientais compreenderem, outras relações humanas com os pares e com o ambiente. Relações vinculadas e enraizadas com à Terra e que se constituem como um forte elemento formativo para a Educação Ambiental.

Palavras-chave: Educação Ambiental; Decolonialidade; Envolvimento Ambiental; Bem Viver; Espaços Sustentáveis

Abstract: To understand the multiplicity of sustainable spaces in the world, I present an Environmental Education that is based on other pedagogies present in traditional communities. By supporting the notion of environmental involvement and Bem Viver, I use decoloniality to update myself in the face of the global health crisis, resulting from the COVID-19 pandemic, with regard to other possibilities of acting as an environmental educator. The results create conditions for environmental educators to understand other human relationships with peers and the environment. Connected and rooted relations with the Earth and which constitute a strong formative element for Environmental Education.

Keywords: Environmental Education; Decoloniality; Environmental Involvement; Well Being; Sustainable Spaces.

${ }^{1}$ Doutor em Ciências do Ambiente. Professor da Universidade Federal da Bahia. E-mail:fpvieira@ufba.br. 


\section{Introdução}

Vivemos um momento, devido à pandemia da COVID-19, que se assenta sobre o mundo, em que é possível questionar o modo de vida de um modelo de humanidade, e as suas relações com a natureza. Entendo ser propício, e este é o objetivo do presente artigo, ampliar a compreensão da existência de uma multiplicidade de espaços sustentáveis existentes na Terra e que já atuam frente à algumas crises ambientais, como a degradação do ambiente, à perda da sociobiodiversidade, dentre outras.

Homens e mulheres em uma relação de envolvimento e enraizamento com outras formas de vida, constroem espaços sustentáveis, que podem ensinar como atuar frente à crise de saúde imposta pela pandemia atual. $E$ neste processo de ensinar percebo a potência de outras pedagogias, para que a Educação Ambiental possa se atualizar e auxiliar na ampliação e divulgação de comunidades sustentáveis já existentes em nosso planeta.

Pedagogias, que serão tecidas neste artigo, com aportes teóricos e epistemológicos decoloniais. A técnicas da narrativa, e da participação observante, estão presente com as quebradeiras de coco. O Bem Viver pensado como suporte epistemológico, emerge para compreensão da dimensão vivida de comunidades originárias na América Latina.

Para tanto, com o intuito de possibilitar a emergência de outras pedagogias as atividades educacionais que estejam relacionadas com 0 ambiente, ou seja, àquelas pertinentes à Educação Ambiental serão àquelas que direcionarei o olhar, para percorrer o caminho de como construir sociedades sustentáveis frente às crises ambientais que vivemos em escala global.

Atividades, para além da ideia de que estas se referem a uma racionalidade produtivista e economicista. Atividade apresentada e entendida como a qualidade do que é ativo, do que é movente, tal qual as diversidades de pedagogias existentes no mundo.

Para tanto as noções de sustentabilidade e natureza serão apresentadas, a partir do entendimento de que há uma pluralidade de espaços, saberes e modos de vida presente na Terra, e que, portanto, não é possível propor uma única maneira para ser sustentável.

\section{A Terra como morada e os conceitos de Natureza e Ambiente}

A Terra ao ser pensada como a morada não permite o seu uso de maneira exploratória. A casa precisa ser compreendida como um espaço que habitamos, que temos vínculos e relações de defesa e pertencimento. Terra que extrapola a dimensão física e utilitária: 
A Terra é o advento do sujeito, fundamento de toda a consciência a despertar a si mesma; anterior a toda objetivação, ela se mescla a toda tomada de consciência, ela é para o homem aquilo que ele surge no ser, aquilo sobre o qual ele erige todas as suas obras, o solo de seu hábitat, os materiais de sua casa, o objeto de seu pensar, aquilo a que ele adapta sua preocupação de construir e de erigir (DARDEL, 2015, p.41).

Nesta perspectiva a Terra se torna um lugar, um espaço de afetividade e de pertencimento no qual os seres humanos constroem suas relações, com os mais diversos elementos que a compõem. Ao realizar um exercício prévio de compreensão da Terra como um lugar vislumbro a possibilidade de que os espaços sustentáveis se constituem de diversas maneiras, tendo como cerne o modo de vida que é alicerçado dos seres humanos em suas vivências com o ambiente.

Ao compreender a Terra como morada, habitat do ser humano, a percebo como um lugar. Um espaço que se constitui a partir de uma vivência, das experiências e significações, pertencimento e envolvimento. Para Relph (1979, p.17) o lugar: "Não se refere a objetos e atributos das localizações, mas a tipo de experiência e envolvimento com o mundo, à necessidade de raízes e de segurança".

Como as experiências são singulares, pois a forma de se relacionar dos seres humanos com a Terra não é homogênea, percebo uma multiplicidade de lugares, que propiciam uma diversidade de formas de pertencimento e envolvimento. Estes lugares possuem uma diversidade de dimensões escalares, que podem variar desde a casa onde moramos até o planeta Terra, como aponta o geógrafo Yi-Fu Tuan (1983).

A partir disto dou um passo para desconstruir a ideia de que o sustentável é único e que deve ser alcançado da mesma forma nos mais diversos lugares, pois a premissa de unicidade do sustentável despreza as singularidades dos territórios, dos lugares e dos sujeitos, que possuem uma riqueza de saberes e modos de vida que se constituem no diálogo com a natureza.

Natureza que na escala macro é tornada mercadoria, e apropriada de maneira exploratória e pautada por uma racionalidade econômica. Racionalidade, que ganha ênfase com a conformação do mundo modernocolonial que teve o seu início, conforme aponta Porto-Gonçalves (2013), a partir da afirmação da Europa como centro hegemônico do mundo no final do século $\mathrm{XV}$, e se mantém até os dias atuais potencializada pelo discurso do desenvolvimento sustentável.

Vieira, 2017, destaca que o desenvolvimento sustentável, com base na ideia de crescimento econômico, surge como àquele capaz de resolver 
problemas sociais, e ambientais e que, em uma lógica global, inviabiliza possibilidades de envolvimento com a natureza a partir de uma diversidade de culturas e de outros processos de significação da natureza que aflora do envolvimento com o lugar.

A natureza se apresenta como um conceito criado pelos homens e mulheres ao longo do tempo e do espaço - e não apenas como uma entidade abstrata, preconizada por uma ciência moderna e consensual, composta de elementos bióticos e abióticos, Vieira (2017). Porto-Gonçalves (2006), associa a construção do conceito de natureza à cultura humana:

Toda sociedade, toda cultura cria, inventa, institui uma determinada idéia do que seja a natureza. Nesse sentido o conceito de natureza não é natural, sendo na verdade criado e instituído pelos homens. Constitui um dos pilares através do qual os homens erguem as suas relações sociais, sua produção material e espiritual, enfim, a sua cultura (PORTOGONÇALVES, 2006, p.23).

Ao pensar na não naturalidade do conceito de natureza aprendi que ao longo do espaço e do tempo, o que se tem é a humanidade priorizando a sua relação com a natureza, a partir de um viés técnico e mecanicista, visando descobrir os seus segredos. Com a construção do mundo moderno-colonial, há uma acentuação da busca por desvelar os segredos do natural, a partir de uma perspectiva cientificista, como aponta Hadot (2006).

Ganha força a ideia de que a natureza é um objeto, ou conjunto de objetos a serem experimentados e validados a serviço da humanidade. Para Artigas (2005), ao criar o método indutivo, Francis Bacon concede a criação de uma trajetória científica de domínio da natureza: "Os segredos da natureza se revelam mais sob a tortura dos experimentos do que no seu curso natural" (BACON, I, 129, citado por HADOT, 2006).

Vieira (2017) destaca que o método fundado por Bacon se torna utilizado por outros cientistas, com o intuito de acentuar as técnicas de dominação da natureza, em uma atitude arbitrária, a partir da ideia de quantificar o real:

[...] com Bacon, Descartes, Galileu, Newton, operou-se uma ruptura definitiva não com as aspirações da magia, mas com seus métodos, e que esses sábios descobriram o meio de avançar de modo decisivo e definitivo nesse projeto de dominação da natureza apegando-se à análise rigorosa do que pode ser medido e quantificado nos fenômenos sensíveis (HADOT, 2006, p.144). 
O exemplo de Bacon é só mais um de como ocorre a objetivação construída do humano sobre a natureza. E é desta maneira que ao longo do tempo, o ser humano busca validar a relação com o natural fazendo com que a dimensão ambiental sirva a uma racionalidade econômica, ao assimilar o discurso ecológico em função de uma lógica econômica.

E o ambiente é um conceito que emerge como uma derivação da natureza, uma vez transfigurada de modo intencional ou inadvertido, de acordo com os propósitos de diferentes grupos sociais, especialmente daqueles preocupados com a acumulação do capital, na qual "a presença do homem concretamente como ser natural e, ao mesmo tempo, como alguém oposto à natureza promoveu/promove profundas transformações na natureza em si mesma e na sua própria natureza" (SUERTEGARAY, 2014, p.119).

Logo, o ambiente é compreendido como uma transfiguração, a passagem de uma figura para outra, e que traz uma ideia de possessão. "Assim, uma natureza possuída pelo homem transfigura-se, adquire uma outra dimensão" (SUERTEGARAY, 2014, p.116). Possessão que é proporcionada pelas técnicas ao intervirem nas formas e processos naturais. Nessa transfiguração, as relações do ser humano sobre a natureza se tornam empobrecidas em uma perspectiva de compreensão da Terra como morada.

\section{Educação Ambiental e a falsa ideia de uma única via para a sustentabilidade}

Na perspectiva de uma racionalidade econômica, que se utiliza de um discurso ambiental e ecológico, se sobrepondo às relações de enraizamento, pertencimento com a natureza e de vinculação da Terra como nossa morada, surge o conceito de desenvolvimento sustentável.

Conceito que busca sustentar o discurso de um desenvolvimento pautado por uma ideia de progresso que contribui para fomentar um modelo de sociedade, que não só degrada a natureza em larga escala, como também empobrece as possibilidades de compreensão da Terra como a morada do humano.

Com o objetivo de manter o status quo desenvolvimentista, surge o conceito de desenvolvimento sustentável. Proposto pela ONU e presente em um documento nominado Nosso Futuro Comum (1991). Tal conceito preconiza que é "[...] aquele que atende às necessidades do presente sem comprometer as possibilidades das gerações futuras atenderem suas próprias necessidades" (COMISSÃO MUNDIAL DO MEIO AMBIENTE E DESENVOLVIMENTO, 1991.p.09).

E este desenvolvimento sustentável, centrado em crescimento econômico e que surge pretensamente capaz de resolver os problemas sociais, tal como o desemprego, e ambientais, Guimarães (2006), em especial por intermédio do uso das denominadas tecnologias "limpas" constitui-se em uma 
racionalidade econômica que, em uma lógica global, inviabiliza possibilidades de envolvimento com a natureza a partir de uma diversidade de culturas e de outros processos de significação que aflora do envolvimento com o lugar. É esta racionalidade que é necessária ser exposta na atual conjuntura social, imposta pela crise de saúde, para que se possa compreender que a lógica produtivista retira as possibilidades de enraizamento com a Terra e com o lugar.

Ao buscar entender como o conceito de desenvolvimento sustentável ressoa na Educação Ambiental, direciono o olhar para as concepções, conservacionista e pragmática, pois compreendo que estas reforçam a ideia de que a criação de "bons" hábitos nos humanos de maneira individualista para com a natureza, e as inserções de novas tecnologias são suficientes para solucionar a degradação ambiental.

A leitura que faço, é que há um grave equívoco na ideia de que novas técnicas solucionarão os problemas ambientais. Entendo, justamente que o uso excessivo das tecnologias - que em uma sociedade capitalista está a serviço do aumento da produtividade e, consequentemente, do lucro - é o responsável por um viés de dominação e de conquista da natureza.

Vieira (2017) destaca que as técnicas cada vez mais submetem os seres humanos a comportamentos previsíveis, por conta de uma racionalidade econômica que subjuga os lugares a uma lógica dominante e global. Isso inviabiliza entender que um dos maiores expoentes do paradigma da modernidade, a crença da tecnologia como panaceia, possa nos permitir construir outra trajetória de relação com a natureza.

Dessa maneira ficamos presos em uma "armadilha paradigmática", (GUIMARÃES, 2006), na Educação Ambiental, na qual há a manutenção de uma racionalidade hegemônica fragmentária, simplista e que reduz a realidade. Educação que se constitui sob as égides do paradigma da modernidade, e fundamentada em uma lógica que põe em pares opostos, elementos que intrinsecamente estão amalgamados na teia da vida, como natureza, cultura, ser humano.

Esta Educação Ambiental traz de maneira bastante homogênea, a ideia de um possível desenvolvimento sustentável que serviria a todos os territórios, de forma igualitária, a partir da premissa de que todos pudessem alcançar um satisfatório desenvolvimento social e econômico. Logo, este modelo de Educação Ambiental induz para que o desenvolvimento sustentável se torne um discurso necessário, sobretudo, aos interesses dos segmentos hegemônicos que conduziram o planeta à degradação ambiental.

E assim ao se alicerçar em torno de aspectos tecnicistas, como se esses fossem capazes de dar conta da problemática ambiental, tal qual delineada até aqui, a Educação Ambiental encobre os reais causadores da problemática ambiental, que se constitui em sua essência a partir da separação ser humano/natureza e da ideia de acumulação e de objetivação construída sobre 
a natureza. Essa construção diminui as possibilidades de pensarmos caminhos de uma real interação entre os sujeitos que constroem a Educação Ambiental com o seu mundo vivido e o seu lugar. Tal diminuição é consolidada à medida que confere, a uma ciência desenvolvida por um viés tecnicista-colonialista e que subjuga uma diversidade de saberes e as subjetividades, o poder de ditar as regras de formação da Educação Ambiental.

As atividades educacionais, vinculadas ao ambiente, pautadas em uma lógica de um único desenvolvimento sustentável e constituída em ações pedagógicas tecnicistas e individualistas passam cada vez mais a estarem sem sentido, a partir da compreensão de um mundo múltiplo e com uma diversidade de formas de se relacionar com a natureza.

Assim, entendendo que o discurso das inovações tecnológicas centradas em uma racionalidade econômica precisa ser revisto, visando diminuir os prejuízos pedagógicos presente na Educação Ambiental pragmática e conservacionista, é imperativo que a Educação Ambiental sustentada por este discurso, precise ter as suas atividades questionadas, não apenas no atual espaço tempo global por conta da pandemia da COVID-19, mas também após à superação desta crise de saúde.

E a Educação Ambiental que tenha como premissa uma lógica do pertencimento, da afetividade e da conexão com a Terra, se coloca como um contraponto de uma educação pautada no individualismo e na fragmentação.

É esta educação que sugiro para permitir a transição das atividades educacionais, voltadas para o ambiente, questionadas até então. Educação Ambiental que se realize de maneira oposta, à uma racionalidade de simplificação do natural, ao compreender que o conhecimento pode ser produzido por um viés existencial e de envolvimento do ser humano com a natureza. Um conhecimento constituído por intermédio do vivido, em que as experiências vividas estejam atreladas a nossa essência e existência no mundo.

\section{A decolonialidade como uma possibilidade}

Compreender que a crise ambiental é também uma crise de produção do conhecimento é uma perspectiva de contrapor à ideia de um único desenvolvimento sustentável. Uma homogeneização que se apresenta como uma imposição em uma relação colonial vigente no nosso mundo. Entendendo que o discurso do desenvolvimento sustentável se alicerça em nossa sociedade e vislumbrando outras possibilidades questiono: quais são os caminhos possíveis para compreender que há uma pluralidade de sustentabilidades já existentes no mundo, e como podemos aprender com elas?

Para adentrar na discussão sobre a multiplicidade de sustentabilidades existentes no mundo utilizo o viés teórico e epistemológico da decolonialidade, 
em busca de ampliar o repertório formativo dos profissionais em Educação Ambiental. $O$ intuito é permitir que os educadores e educadoras ambientais se abram para outras pedagogias existentes e que possam se desconectar de uma perspectiva de Educação Ambiental tecnicista.

Assim, com Leff (2006), apresento uma teorização sobre a crise ambiental, que visa, romper com o paradigma da modernidade:

[...] a crise ambiental problematiza os paradigmas estabelecidos do conhecimento e demanda novas metodologias capazes de orientar um processo de reconstrução do saber que permita realizar uma análise integrada da realidade (LEFF, 2006, p.60).

Paradigma que é fundado em uma colonialidade cujo padrão de poder, que passa a governar o mundo, tem como evento central a invasão do continente americano pelos europeus a partir do final do século XV, e que se constitui em um sistema que dá início a uma primazia de organização de mundo à Europa. Vieira (2017) aponta que este mundo não é mais a Europa, em termos espaciais e territoriais. Assim, Quijano e Wallesrtein (1992 apud MIGNOLO, 2005) denominaram este sistema, como: sistema mundo modernocolonial.

As bases para a consolidação deste mundo tiveram como pilares a colonização do continente americano, com a escravização de diversos povos, sobretudo os indígenas, bem como negros sequestrados da África, continente que posteriormente passa a ser objeto espacial para a consolidação do mundo moderno-colonial. Isso ocasionou a destruição, em larga escala, das florestas da América, seja para a retirada de metais preciosos como ouro e prata, seja para a implantação das monoculturas, o que deu início ao processo de espoliação da natureza em larga escala.

Esse mundo baseou-se também na expropriação de diversos povos originários do seu território, criando territorialidades que servem ao interesse restrito dos países centrais que controlam o mundo moderno-colonial. Um entendimento de que os territórios a serem conquistados, apoiando-se em uma vertente economicista, fossem utilizados como fonte de recursos e incorporados ao progresso e desenvolvimento a partir da relação de poder imposta pelos invasores, negando a cultura dos povos ali existentes.

$\mathrm{Na}$ busca pela construção de outras possibilidades de produção de conhecimento, tendo como base um diálogo entre saberes, e o reconhecimento de que as sustentabilidades são múltiplas, tais quais os espaços e as culturas, emerge a necessidade de compreender que, pelo fato de a maior parte do mundo não estar inclusa no ideal de progresso do mundo colonial, trago a epistemologia pós-colonial, definida por Santos (2010) como: 
[...] um conjunto de correntes teóricas e analíticas, com forte implantação nos estudos culturais, mas hoje presentes em todas as ciências sociais, que têm em comum darem primazia teórica e política às relações desiguais entre o Norte e o Sul na explicação ou na compreensão do mundo contemporâneo (SANTOS, 2010, p. 28).

Vieira (2017), destaca que o diálogo entre saberes cria condições para um exercício de desconstrução do mundo moderno-colonial, ao permitir que outros saberes, que historicamente foram considerados uma maneira de produção de conhecimento menos válida do que o conhecimento científico, possam emergir nos espaços de discussão e produção do conhecimento.

E o lugar ao ser possuidor de singularidades, mas que ao mesmo tempo não existe isolado por si só, à medida que permite ao ser humano manter-se conectado com outros lugares do mundo, com o próprio ser e com a Terra, é a escala de vida prioritária para outras possibilidades de produção do conhecimento. É no lugar que há uma emergência de saberes, que ocorre como um contraponto ao processo de formação de conhecimento do mundo moderno-colonial. Saberes que se contrapõem, no vivido, a ideia de um único conceito de desenvolvimento sustentável.

Ao concordar com Capra (1997), para o qual os paradigmas são constelações de concepções, de valores, de percepções e de práticas compartilhadas por uma comunidade, que dá forma a uma visão particular da realidade é que acredito importante apresentar as potências de pedagogias possíveis nas práticas e valores constituídos em comunidade como outras possibilidades de atualizações de discursos e ações do ser humano para com a natureza. Com estas possibilidades, busco uma desconstrução paradigmática, visando propiciar ao lugar, um espaço de destaque em que o entendimento do sustentável seja visível e perceptível como outra possibilidade de interação entre a humanidade e a natureza.

Com esta perspectiva decolonial há elementos teóricos-conceituais e epistemológicos para ampliar a formação dos educadores e educadoras ambientais, possibilitando ler um mundo em que existe uma diversidade de sustentabilidades presentes, 0 que permite ir além da ideia de um desenvolvimento sustentável único, tal qual proposto pela ONU.

\section{Envolvimento ambiental e múltiplas pedagogias}

Após o entendimento que o desenvolvimento sustentável é um conceito criado por um modelo de sociedade que não leva em consideração os diversos saberes, singularidades, lugares e potencialidades de envolvimento e pertencimento com 0 ambiente, neste tópico busco apresentar algumas possibilidades de sustentabilidades, para além de um ideal desenvolvimentista e como que uma outra racionalidade pode auxiliar na compreensão destas 
outras sustentabilidades. Para tanto, sugiro que educadores e educadoras ambientais estejam abertos para que as possibilidades de outras sustentabilidades façam parte da ampliação do seu repertório formativo.

Proponho que esta abertura passe, também, pela noção de envolvimento ambiental, que construí na tese de doutorado, em que:

Tal perspectiva - por mais que as palavras possam indicar uma redundância à medida que o ambiente nos envolve, nos circunda - refere-se a outro viés relacional com o ambiente, no sentido de percebê-lo e valorá-lo em uma perspectiva de construir um elo com a natureza. Perspectiva pautada por uma ética ambiental e orientada por um trato no qual o cotidiano e o vivido sejam fundantes. É um relacionar-se de modo diverso, a partir de outros preceitos e propósitos (VIEIRA, 2017, p.19).

Envolvimento, constituído por alguns pilares existentes nos modos de vida de comunidades tradicionais, em que emerge um sustentável que se realiza no vivido. Estes pilares envolvem a autossuficiência, pensada como um sustento em busca de uma dignidade; a conservação ambiental, que se efetiva a partir de uma resistência em defesa do ambiente, pois só com este ambiente é possível construir sua cultura; a solidariedade de cada um para com a natureza e para com os próprios humanos e que se realiza de maneira horizontal entre estes pares; e a justiça social, que se assenta em uma luta pelo direito de uso do território (VIEIRA, 2017, p.20).

O entendimento que outros caminhos para a sustentabilidade ambiental são necessários, perpassa a partir da noção de envolvimento ambiental, pela necessidade de rompimento com uma perspectiva de que a globalização econômica é algo dado, irreversível, e que, portanto, diante de tal situação, só resta moderar os impactos de uma economia que mercantiliza tudo, inclusive a natureza.

Assim, Leff propõe uma sustentabilidade que se baseie em uma política da diversidade e que busque romper com

[...] o regime universal e dominante do mercado como medida de todas as coisas, como princípio organizador do mundo globalizado e do próprio sentido da existência humana. Desconstruir o paradigma da economia é desmascarar a ficção e perversão contidas na retórica do discurso da globalização pensar globalmente e agir localmente -, que na prática leva a impor a lógica do mercado no local, a incorporá-la em todos os poros de nossa pele e de nossa subjetividade, a inseri-la nos resquícios de nossa sensibilidade e de nossa intimidade. (LEFF, 2010, p.26). 
Para romper com a fragilidade da ideia de um modelo desenvolvimento sustentável, que se encontra alicerçado em uma possível desmaterialização da produção, é preciso pensar em outra racionalidade, para além da produtiva (Leff, 2010).

Por este motivo, trago a racionalidade ambiental pautada na economia ecológica presente em unidades de conservação no Brasil e em outros modos de vida existentes na América Latina, como os vividos em movimentos sociais indígenas na Bolívia, no Peru e no Equador e de camponeses em todo território latino americano.

Logo, as possibilidades de mudanças de paradigmas passam necessariamente pela valorização do lugar, tendo como base as diversidades culturais de povos que se relacionam com a natureza, em uma racionalidade ambiental que se constitui em uma epistemologia ambiental, que é:

[...] pensar o saber ambiental na ordem de uma política da diversidade e da diferença, rompendo o círculo unitário do projeto positivista, para dar lugar aos saberes subjugados, para desvelar a retórica do desenvolvimento sustentável[...] (LEFF, 2010, p.187).

Ao expor as intencionalidades da ideia de desenvolvimento sustentável, gestada em um modelo de sociedade que se baseia no controle e domínio da natureza e que alicerça na necessidade de expandir a economia de mercado, é que me apoio em uma episteme, oposta à esta ideia: uma que se constitua na relação do ser humano com a natureza. Uma maneira de produção do conhecimento, que se realize a partir da interação e envolvimento com o ambiente e que permita possibilidades de pensarmos o ser sustentável a partir das multiplicidades de saberes existentes no mundo.

Uma racionalidade ambiental, como propõe Leff (2006) que se sustenta nas transformações do conhecimento ao mobilizar um conjunto de saberes técnicos e práticos associados ao reconhecimento e na valorização dos elementos que compõem o natural, é o que dará o suporte de como a sustentabilidade se realiza, a partir dos modos de vidas de uma diversidade de comunidades tradicionais existentes, para além do mundo da sociedade moderna-colonial.

A produção e aplicação de conhecimentos com o fim de satisfazer as necessidades sociais das comunidades rurais, respeitando seus valores culturais e desenvolvendo o potencial produtivo de seus ecossistemas e de seus saberes práticos implica a necessidade de construir novos princípios de produtividade sustentável, integrando ao conceito de produção os processos ecológicos e culturais que the servem de suporte (LEFF, 2006, p.87). 
Logo, a racionalidade ambiental constitui-se em um processo político e social que passa pela produção de novos conceitos e conhecimentos e conformada por processos sociais, emergindo como um projeto social de resposta a outra racionalidade e apoiando-se mais na legitimação de seus valores, como economias autônomas, da pluralidade étnica, e de processos democráticos de tomadas de poder.

Por conseguinte, emerge um saber fundado a partir da diversidade cultural e identitária, que valoriza o conhecimento singular, subjetivo: "O saber ambiental reconhece as identidades dos povos, suas cosmologias e saberes tradicionais como parte de suas firmas culturais de apropriação de seu patrimônio de recursos naturais" (LEFF, 2006, p.169).

Ao reconhecer a incompletude do conhecimento, é com o saber ambiental que busco, em uma rede de relações, trazer para o debate, no campo das sustentabilidades existentes, outras formas de se relacionar com o ambiente. Formas pautadas na racionalidade ambiental que se constitui no diálogo entre saberes de comunidades diversas que alicerçam seu saber, e seus modos de vida a partir de uma relação de pertencimento e envolvimento com o ambiente.

Com esta racionalidade emerge uma diversidade de pedagogias que reconhecem as multiplicidades de experiências vividas por cada ser, em âmbito coletivo, como bem aponta Arroyo (2014): "Outros saberes de experiências feitos nessa pluralidade de sujeitos que disputam as instituições do conhecimento. Reconhecer esses Outros Sujeitos pressiona por Outras Pedagogias" (2014, p.223).

São pedagogias que se realizam em um processo dialógico do ser humano com 0 ambiente e que trazem para 0 debate 0 Outro, que historicamente foi subjugado pelo mundo da modernidade e da colonialidade. Um Outro que é indígena, quilombola, ribeirinho, pescador, periférico, camponês, quebradeira de coco, açaizeiro, seringueiro, e tantos outros povos que coexistem de maneira íntima e pertencida com o ambiente.

Com estas pedagogias, há uma vivência de uma multiplicidade de culturas. Vivência que não se revela, exclusivamente, em rituais, mas sobretudo enquanto diversidade epistemológica.

Reconhecer a diversidade cultural que coloca na agenda política e pedagógica a presença dos coletivos diversos, seja como educandos, seja como movimentos sociais, culturais exige o reconhecimento da diversidade de experiências, de mundo, de pensamentos, de saberes, de formas de pensar" (ARROYO, 2014, p.113).

Assim é que caminho para o entendimento de que a Educação Ambiental pode se constituir em uma relação pedagógica que favorece as 
potências do ser, do vivido, da organização ecológica e das formas de significação da natureza que se expressam e se manifestam na existência. Uma Educação Ambiental que seja um processo dialógico que abre as possibilidades para que possam compreender uma diversidade de sustentabilidades.

A construção de uma racionalidade ambiental e o aprendizado com as pedagogias constituídas por diversos povos e comunidades tradicionais permitem que as atividades educacionais sejam mais pertinentes à uma Educação Ambiental que se atualiza com a diversidade de comunidades sustentáveis existentes no mundo, rechaçando o discurso de unicidade de um desenvolvimento sustentável.

\section{Saberes e envolvimento ambiental de comunidades tradicionais: o Bem Viver}

Ao destacar que os saberes construídos em comunidades tradicionais e povos do campo, constituem-se em Pedagogias próprias e que se realizam a partir de uma relação de envolvimento de homens e mulheres para com a natureza, apresentarei espaços sustentáveis, presentes em comunidades tradicionais (em uma postura decolonial, tais espaços se localizam na América Latina), com o intuito de se opor as atividades educacionais de uma Educação Ambiental desconectada com o lugar e com a natureza.

Assim, sugiro aos educadores e educadoras ambientais, uma abertura para aprender com saberes que historicamente foram subjugados e que são espaços autônomos na realização do sustentável e, por conseguinte criar uma mudança de perspectiva e de postura que permita pensar sociedades sustentáveis frente às crises ambientais, sobretudo de saúde, tal como a pandemia da COVID-19.

No Brasil, diversos movimentos camponeses criaram um modelo de unidade de conservação da natureza em que as populações tradicionais construíram os seus modos de vida em uma relação de pertencimento com a natureza. Trata-se das reservas extrativistas, que têm a sua figura jurídica criada por meio do decreto presidencial $n^{\circ} 98.897$, de 1990. Neste, as reservas são "espaços territoriais destinados à exploração autossustentável e conservação dos recursos naturais renováveis, por população extrativista"

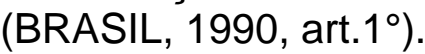

Em uma proposta comunitária, de reforma agrária, na década de 1980, seringueiros liderados por Chico Mendes buscaram a demarcação do território levando em consideração os limites dos rios, igarapés, castanhais, seringais e demais componentes da floresta dos quais os extrativistas faziam uso. Mais do que defender o verde, a natureza a luta dos extrativistas era pela manutenção da vida e pelo direito à terra e, consequentemente, à Terra, o que evidencia, a não separação entre natureza e cultura. 
Assim, diversas populações extrativistas definem uma proposta endógena de uso do território que teve como alicerce os saberes que foram, ao longo de suas experiências vividas, construídos com 0 ambiente. Por conseguinte, emerge a reserva extrativista:

Surgiu da necessidade de se construir uma proposta que correspondesse à vivência dos que lutavam que incorporasse a sua cultura. Rigorosamente não veio de fora. Ao mesmo tempo, essa proposta haveria de dialogar com a sociedade abrangente, com seus códigos próprios que, tradicionalmente, foi construindo excluindo essas populações. [...] a terra é comunitária posto, que na Resex, ela é propriedade da União mas com direito de usufruto por parte das famílias, por meio de suas entidades organizadas que formularão o seu plano de uso (PORTO-GONÇALVES, 2012, p.133).

Em uma proposta construída por meio do vivido dos extrativistas, que possuem um saber constituído com o ambiente, emerge mais do que um conceito, uma forma de organização territorial, autônoma e que visa à manutenção da vida humana com dignidade e solidariedade, pautada por uma justiça social, que por sua vez ressoa em uma defesa do ambiente, se constituindo fortemente em um espaço sustentável.

A pedagogia presente na reserva extrativista do Extremo Norte do Tocantins, com base no envolvimento ambiental, constitui-se em um espaço sustentável. Espaço que se realiza a partir de uma ampla conexão com o babaçual, e que pude perceber durante mais de quatro anos em que atuei como membro do Conselho gestor da referida RESEX.

São migrantes, em sua maioria, oriundos do Maranhão, Piauí e Ceará, mas, também de outros estados do Nordeste, sendo muitos destes descendentes de indígenas, em busca de terras desocupadas para a prática da agricultura e do extrativismo, Velho (1981), que criam a reserva extrativista do Extremo Norte do Tocantins.

Situada ao norte da estrada TO-496 e ao sul do rio Tocantins, na divisa com o Estado do Pará, a oeste, e com o Estado do Maranhão, a leste, foi criada pelo decreto $n^{\circ} 535$, de 20 de maio de 1992. A população desta RESEX é de 893 pessoas, de acordo com um estudo técnico, realizado pela UFV/ICMBio (2014). Todos os habitantes estão no entorno da reserva, pelo fato de que não há regularização fundiária, e, consequentemente, não são permitidas a formação de comunidades, no interior da reserva.

Nesta RESEX a criação de um espaço sustentável ocorre a partir de estratégias cotidianas dos extrativistas para a defesa do babaçual, por intermédio da luta em favor do babaçu livre, e no envolvimento existente entre eles e o ambiente. Um conjunto de saberes, que conformam uma pedagogia que é constituída, em um aprender fundado em uma relação cultural 
intergeracional, que, em especial, permite um conhecimento para trabalhar com o coco babaçu.

Uma quebradeira de coco da RESEX Extremo Norte do Tocantins, que tive a oportunidade e o prazer de me ensinar sobre os modos de vidas e a relação de envolvimento ambiental, foi Caieira. O nome fictício, não é uma mera supressão do verdadeiro nome de uma quebradeira de coco. Ele revela um significado vivido e de pertencimento desta mulher, com seu lugar.

Caieira, se refere a um forno artesanal, produzido pelos extrativistas. Com esta quebradeira de coco, aprendi que este forno se constrói a partir da abertura de um buraco feito no solo, no qual as cascas são condicionadas em um barril de metal que se encaixa nesses buracos. Por fim, as cascas do coco babaçu são abafadas com folhas da palmeira do babaçu e com a própria terra.

$\mathrm{O}$ aprendizado que tive com Caieira permitiu que eu percebesse que a relação teoria e prática é tão imbricada, tão real, tão vivida, que veio à minha mente a constituição de uma pedagogia extremamente didática e potente para a Educação Ambiental.

Caieira, não hesita em falar da importância do babaçual, para a sua vida. "É dele que nós tira o coco. O coco representa muita coisa, pois dele nós tira o azeite, nós tira o óleo, nós faz o sabão, nós faz o carvão pra cozinhar. Representa muita coisa. Representa a renda da família da gente. Ah, tem também o uso da palha, pra cobrir a casa" (CAIEIRA, 2015).

Os saberes constituídos no envolvimento ambiental de Caieira não separam teoria e prática e se alicerçam em uma junção de natureza e cultura, pois uma só existe em função da outra, de maneira ecológica.

Assim aprendi com Palha, mais uma vez, o nome fictício foi dado por minha percepção e minhas experiências em Extremo Norte, a partir do rico uso da palha do babaçual para a construção de cercas e coberturas de casas, artesanatos, dentre outros usos, a importância do babaçual para a vida, a partir do seu envolvimento com o ambiente, e da dor referente à perda das palmeiras, entendida como algo que faz parte da condição humana das quebradeiras de coco.

"O coco pra mim é minha mãe, é meu pai, é minha irmã, é tudo. Do coco nós tira o carvão, nós tira o azeite, nós tira o estrume até pro canteiro. Nós vamos acabar? Nós não pode fazer isso. Nós não temos nem gado, nós vamos acabar com meu cocal? Nunca! O coco é tudo, o coco é nossa vida. Até um remédio pra nós comprar, nós tira do dinheiro do coco. Doi demais quando vejo derrubar as palmeira. Eu choro quando vejo alguém derrubar uma palmeira. Se um não precisa, eles têm que saber que nós precisa. Que eles tão matando uma mãe de família. Derrubar um pé de coco carregado de coco é o mesmo que matar uma mãe de família (Palha, 2016). 
A força nas palavras de Palha, ao colocar o coco babaçu como um ente familiar, demonstra que a realização de um espaço sustentável na RESEX, é tecida em um envolvimento ambiental. Palha assevera uma vida imbricada com o coco, por este ser parte do seu modo de vida, do seu cotidiano e consequentemente, mais do que um mero recurso natural. Ele é o máximo que algo ou alguém poderia ser para outrem: vida!

Enrique Leff, ao compartilhar sua experiência em um evento, o Primeiro Encontro sobre a Sustentabilidade na Perspectiva dos Povos Indígenas, realizado em La Paz, na Bolívia, traz mais uma forma de organização comunitária que constitui uma pedagogia, que por sua vez, se torna um espaço sustentável, a partir do seu vivido:

Ali participamos Carlos Walter Porto, Boaventura de Sousa Santos e outros amigos e colegas, falando em um palco com um público indígena de mais ou menos 200 pessoas, com líderes indígenas de uma lucidez impressionante, que nos olhavam com estranheza quando proferíamos nossos discursos intelectuais sobre a sustentabilidade; de uma sustentabilidade forjada na diversidade cultural. Discursos aos quais eles, indígenas, nos responderam: há muito tempo nós temos nossa forma de significar isso que vocês chamam de sustentabilidade, convivência e equidade; para nós, isso significa simplesmente " viver bem", e se nos deixam "viver bem" segundo nossas visões de mundo e formas de vida, seremos sustentáveis (LEFF, 2010, p.104).

No encontro citado, Leff revelou a necessidade de ouvir e aprender com os saberes presentes com os povos indígenas da Bolívia que ao reivindicarem os valores e saberes ancestrais como constituintes dos processos políticos decisórios no Estado boliviano criam movimentos e entidades representativas para a inclusão destes saberes e valores constituídos com a natureza, visando uma efetiva transformação do Estado.

Para Leff (2010) é na gestão do seu próprio território que os povos tradicionais da Bolívia constroem sua própria sustentabilidade a partir de suas cosmovisões de mundo. Logo, com Leff (2010) defendo o aprendizado com os conceitos que são fundadores das culturas indígenas da América Latina, a partir de seu lugar, a partir de sua própria cultura.

Assim é no sentimento de uma unidade comum de um Bem Viver que os povos indígenas vivem em uma "comunitarización universal y total de todas las relaciones humanas y de los humanos con la naturaleza" (LINERA, 2015, p. 69). Um dos aspectos fundamentais nesse processo de conexão do humano com o natural, é a radicalização democrática e comunitária que crie condições 
para uma articulação entre representação, participação e autonomias na formação do Estado, Linera (2015).

Acosta (2016) ao apresentar a ideia de que com o Bem Viver é preciso uma busca de alternativas de vida forjadas no calor das lutas populares, particularmente dos povos e nacionalidades indígenas, traz que estas ideias são:

surgidas de grupos tradicionalmente marginalizados, excluídos, explorados e até mesmo dizimados. São propostas invisibilizadas por muito tempo, que agora convidam a romper radicalmente com conceitos assumidos como indiscutíveis. Estas visões pós-desenvolvimentistas superam as correntes heterodoxas, que na realidade miravam a "desenvolvimentos alternativos", quando é cada vez mais necessário criar "alternativas de desenvolvimento". É disso que se trata o Bem Viver. (ACOSTA, 2016, p.70).

Com estas palavras de Acosta, entendo que as pedagogias dos povos latinos que constituem o Bem Viver permitem a reelaboração de conceitos e noções amplamente difundidas na Educação Ambiental, em especial o desenvolvimento sustentável. Diversos saberes indígenas não possuem a partir de uma racionalidade econômica, um conceito análogo ao de desenvolvimento.

A linha da vida, de uma modernidade, como uma reta do tempo que vai do atrasado ao moderno, do subdesenvolvido ao desenvolvido, não faz parte do escopo dos saberes de comunidades indígenas. Portanto com o Bem Viver é possível reconstruir a ideia do que é sustentável, tendo como elementos a diversidade de códigos e de representações do vivido em relação ao natural, em suas práticas cotidianas. Práticas que se alicerçam na complementariedade e na solidariedade entre todos os seres vivos, e na construção de noções ligadas ao seu modo de vida, como o:

sumak kawsay das tradições indígenas se distancia de conceitos ocidentais que concebem o surgimento da vida política a partir de uma ruptura inicial ou da separação ontológica em relação à Natureza. Dito de outra maneira, o Bem Viver não concorda com o princípio da desnaturalização das realidades humanas (Cortez, citado por Acosta, 2016)

O Bem Viver emerge em comunidades originárias do Equador, com o nome de sumak kawsay. $\mathrm{E}$ ao nascer na margem da periferia do mundo econômico e do conhecimento científico, esta noção não se baseia na racionalidade econômica de uma pretensa ideia de desenvolvimento. Tortosa (2009) aponta que a ideia provém do vocabulário de povos totalmente 
marginalizados, excluídos de respeitabilidade e cuja língua era considerada inferior, inculta, incapaz de pensamento abstrato, primitiva.

São com estes povos que tem o Bem Viver como uma filosofia de vida, de envolvimento com ambiente em períodos anteriores ao surgimento do Estado moderno e que representam culturas que sobreviveram ao epistemicídio na América latina, que vejo a Educação Ambiental com possibilidade de ampliar no seu repertório o que é um espaço sustentável. Por isso, é importante aprender com as experiências e lições comunidades que constituem um mundo marginalizado, mas, que são detentoras de modos de vida que gerem o ambiente em uma relação de respeito e empatia com as formas de vida.

\section{Considerações Finais}

Entendo, que as contribuições de comunidades não indígenas que encontraram formas de se envolver com o ambiente dentro das próprias estruturas de um processo de colonização e de uma colonialidade do poder, podem se constituir em Um Bem Viver. Logo, coloco a dimensão vivida das mulheres quebradeiras de coco, defensoras de um ambiente e de um modo de vida, como um efetivo exercício do Bem Viver.

São com os dois exemplos apresentados no texto, como formas culturais de envolvimento ambiental em diferentes lugares, mas que se conectam a partir de um mundo colonizado e que historicamente teve seus saberes subjugados, que busquei apresentar possibilidades de atividades formativas voltadas para educadores e educadoras ambientais ampliarem seus repertórios pedagógicos, de como é possível auxiliar na construção de Sociedades Sustentáveis frente às crises ambientais que vivemos na Terra.

A abertura para aprender com outras pedagogias, em especial de povos e comunidades tradicionais, a possibilidade de compreensão da Terra como nossa morada, e a perspectiva de envolvimento ambiental, associadas à uma criticidade à ideia do que é natureza e como esta se transfigura no ambiente, são caminhos que apresentei como possibilidades de conformação de uma Educação Ambiental que auxilie na formação de uma sociedade mais justa, entre os humanos e entre estes e o natural.

Para esta abertura, busquei desconstruir uma perspectiva de que a Educação Ambiental deve vir a ser constituída, de maneira exclusiva, sob a égide do mundo moderno-colonial, em que a criação de um único conceito de desenvolvimento sustentável, pudesse dar conta da pluralidade de envolvimentos e saberes ambientais constituídos nos mais diversos espaços.

E, ao apresentar o envolvimento ambiental alicerçado a partir de modos de vida presentes em comunidades tradicionais e do campo, buscando romper, em um exercício decolonial, com a premissa de que existe apenas uma única maneira de se tornar sustentável, o intuito é o de como educadores e 
educadoras ambientais podem transitar para outras atividades educacionais, para além do espaço tempo em que vivemos a pandemia da COVID-19, aprender com outras comunidades sustentáveis já existentes na Terra.

Portanto, é com estas comunidades que acredito ser possível a suspensão de atividades voltadas para uma Educação Ambiental tecnicista e individualista. Ao mesmo tempo visualizo, uma potência para que com as múltiplas territorialidades existentes no mundo a Educação Ambiental possa se alicerçar em uma premissa de que os espaços sustentáveis estão para além de um viés mercadológico, e que inclua em sua definição a riqueza dos saberes e da sociobiodiversidade existentes com várias comunidades.

\section{Referências}

ARROYO, M.G. Outros Sujeitos, outras pedagogias. 2.ed. Petrópolis: Vozes, 2014.

ARTIGAS, M. Filosofia da Natureza. São Paulo: Instituto Brasileiro de Filosofia e Ciência Raimundo Lúlio, 2005.

BRASIL. Decreto no 98.897, de 30 de janeiro de 1990. Dispõe sobre as Reservas Extrativistas e dá outras providências. Disponível em: < http://www.planalto.gov.br/ccivil 03/Decreto/Antigos/D98897.htm >. Acesso em: 23 de maio, 2020. Brasília, 1990.

CAPRA, F. A teia da vida. São Paulo: Cultrix, 1997.

COMISSÃO MUNDIAL SOBRE MEIO AMBIENTE E DESENVOLVIMENTO. Nosso futuro Comum. Rio de Janeiro: Fundação Getúlio Vargas, 1991.

DARDEL, E. O Homem e a Terra: natureza da realidade geográfica. Tradução de Werther Holzer. São Paulo: Perspectiva, 2015.

GUIMARÃES, M. Armadilha paradigmática na Educação Ambiental. In: LOUREIRO, C. F. B; LEROY, J. P. (Orgs.). Pensamento complexo, dialética e Educação Ambiental. São Paulo: Cortez, 2006.

HADOT, P. O Véu de Ísis: Ensaio sobre a história da ideia de natureza. São Paulo: Loyola, 2006.

LEFF, E. Epistemologia Ambiental. 4. ed. São Paulo: Cortez, 2006.

LEFF, E. Discursos Sustentáveis. Tradução de Silvana Cobucci Leite. São Paulo: Cortez, 2010.

LINERA, A.G. Socialismo Comunitário: Un Horizonte de Época. La Paz: Vicepresidencia, 2015.

MIGNOLO, W. A colonialidade de cabo a rabo: o hemisfério ocidental no horizonte conceitual da modernidade. In: LANDER E. (Org.). A colonialidade do saber: eurocentrismo e ciências sociais - Perspectivas latino-americanas. Buenos Aires: Clacso, 2005. 
PORTO-GONÇALVES, C. W. Os (des)caminhos do Meio Ambiente. 15. ed. Contexto: São Paulo, 2006.

PORTO-GONÇALVES, C. W. Amazônia: Amazônias. 3. ed. Contexto: São Paulo 2012.

PORTO-GONÇALVES, C. W. A Globalização da natureza e a natureza da globalização. $5^{\circ} \mathrm{ed}$. Rio de Janeiro: Civilização Brasileira, 2013.

RELPH, E. As Bases Fenomenológicas da Geografia. Geografia. Rio Claro, v.4, n.7, p.1-25, 1979.

SANTOS, B. S. A Gramática do Tempo: para uma nova cultura política. 3. ed. São Paulo: Cortez, 2010.

SUERTEGARAY, D. M. A. Espaço Geográfico Uno e Múltiplo. Scripta Nova Revista electrónica de geografía y ciencias sociales. Universidad de Barcelona, n. 93, p.1-11, 2001.

TORTOSA, J.M. Sumak Kawsay, Suma Kamaña, Buen Vivir. Fundación Carolina, Madrid, 2009.

TUAN, Yi-Fu. Espaço e lugar: a perspectiva da experiência. Tradução de Lívia de Oliveira. São Paulo: Difel, 1983.

UFV/ICMBio. Apoio ao processo de identificação das famílias beneficiárias e diagnóstico socioprodutivo em Unidades de Conservação Federais. Viçosa-Brasília, 2014.

VELHO, O.G. Frentes de expansão e estrutura agrária: estudo do processo de penetração numa área da Transamazônica. 2 ${ }^{a}{ }^{a} e d$. Rio de Janeiro: Zahar, 1981.

VIEIRA, F.P. Envolvimento e Educação Ambiental com as quebradeiras de coco: Um caminho sustentável na reserva extrativista do Extremo Norte do Tocantins. 2017, 199p. Tese (Doutorado em Ciências do Ambiente), Universidade Federal do Tocantins, Palmas, 2017. 